\title{
Different Worlds, Mutual Expectations: African Graduate Student Mothers and the Burden of U.S. Higher Education
}

\author{
Jane-Frances Y. Lobnibe ${ }^{1}$ \\ ${ }^{1}$ Department of Education, University for Development Studies, Wa-Campus, Ghana \\ Correspondence: Jane-Frances Lobnibe, Box UPW 36, Wa Campus, Ghana. Tel: 233-54-092-0210. E-mail: \\ jlobnibe@gmail.com
}

Received: October 6, 2012

Accepted: March 19, 2013 Online Published: May 16, 2013

doi:10.5539/jel.v2n2p201

URL: http://dx.doi.org/10.5539/jel.v2n2p201

\begin{abstract}
In the United States, colleges use the internationalization of their student body as a conduit to achieving greater diversity. Not only has the attraction of international students become a priority for many universities regardless of size or location, universities administrators are often also quick to point to the increasing number of international students as evidence of their commitment to diversity efforts. This paper explores African student mothers' experiences with the US higher education system by examining both the structural environments and the socio-cultural burdens and constructs that affect and shape their learning and adjustment challenges in predominantly white US universities. It argues that while individual behaviors and attitudes may present serious challenges to the adjustments and full integration in US colleges, it is largely the structural and institutional arrangements and policies (both written and unwritten) that often prove difficult to navigate. Drawing on the experiences of twenty-three women from a predominantly white Midwestern university, it demonstrates that policies and arrangements that place the distribution of material, social and academic resources on students' ability to network in unequal social environments often place extra burden on the African graduate student mother studying in US higher institution; how these students in turn respond, interpret and negotiate their experiences will be highlighted.
\end{abstract}

Keywords: higher education, internationalization, student mothers, Africa

\section{Introduction}

In the United States (US), higher education institutions have increasingly used diversity as a cornerstone of their mission statements and in their efforts to attract students from different backgrounds. In these efforts, attracting international students has become a priority for universities regardless of size or location; colleges have sought not only to use the internationalization of their student body as a conduit to achieving greater diversity, they are often quick to point to the number of international students as evidence of their commitment to diversity efforts. To be sure, a significant change in contemporary higher education the world over is a substantial increase in the number of international students. While African men and women have been part of this increasing flow, they represent a recent entry into US international education sphere, compared to students from other regions. In the case of African women, the focus of this paper, their entry has been made possible by an unintended result of modifications of US immigration laws which allow them to participate in stepwise fashion; often following their spouses (who are often students) and gradually enrolling in higher institutions.

In this paper, I explore both the structural environments and the socio-cultural burdens and constructs that affect and shape the experiences of African graduate student mothers in predominantly White US universities. I argue that while individual behaviors and attitudes may present serious challenges to the adjustments and full integration of students in US colleges, it is largely the structural and institutional arrangements and policies (both written and unwritten) that often prove difficult to navigate. Policies and arrangements that place the distribution of material, social and academic resources on students' ability to network in unequal social environments often place extra burden on African graduate student mothers studying in US higher institutions. To this end, the extent to which the organizational policies and practices of host institutions and departments shape the daily experiences of this group of international students and how they in turn respond, interpret and negotiate their experiences will be highlighted. 


\section{Research Context and Methodology}

The material upon which this paper draws its analysis is based largely on oral and life history interviews I conducted with individual female international students in a large US public research university in the mid-western region that ranks among the top ten universities hosting the most number of international students in the country between 2007 and 2009 (Note 1). I administered brief questionnaires and held focus groups and extended conversations with individual female graduate students to elicit their views and life experiences studying in the US. I employed both opportunistic and snowball sampling, a method in which potential respondents learned about the study from people I already interviewed; this method proved very effective in gathering data as it allowed potential women to readily welcome or also contact me to share their personal experiences since they already had knowledge of the interview process from those I already interviewed. To gain insights into some of the early challenges new arrivals faced,

I also spent some time in the international student office, observing student interactions with international student office staff during check-ins.

I transcribed the interviews, then analyzed and interpreted them using the constant comparative approach (Strauss \& Corbin, 1990). An inductive approach was used to analyze data in which common themes and emerging patterns were identified using content analysis. With this technique "the patterns, themes, and categories of analysis come from the data; they emerge out of the data rather than being imposed on them prior to data collection and analysis" (Patton, 1980, p. 306).

Common qualitative tools and techniques of triangulation and thick description were also used. (Lincoln \& Guba, 1985) Theory triangulation relies on the use of multiple perspectives to interpret data. In this study, I relied on research emerging from the fields of sociology, organizational behavior, and higher education to triangulate the data. Study participants were selected to review and analyze working themes to ensure they reflected individual experiences and the feedback was incorporated into the final narrative (Janesick 2000).

\section{Different Worlds, Mutual Experiences}

In her study about mature student women, Edwards (1993) notes that concern among educationalists has not just centered on pondering the effects of gaining an education upon these women's family lives but that their family responsibilities are often regarded as interfering with their ability to study. In such cases, mature student women's experiences are often discussed in ways that situate their lives as externalities and "bag and baggage" that impact negatively on their studies. Moreover, any problems the women may experience in combining family and education are conceptualized in particular ways which place the onus for dealing with them upon the women themselves. For instance, because accounts of women's lives and experiences and related notions of female identity are often structured by the juxtapositions of the public sphere with the private sphere, it is hardly surprising that Higher education has been structured and practiced based on an image of the ideal student as the unfettered white male who is believed to be capable of rendering undivided commitment to academic pursuits (Leathwood, \& O'Connell, 2003).

The idea of a family sphere that is private and is women's special responsibility is both deeply ingrained and emotionally loaded, to the extent that acute discomfort or guilt can be felt if the norms are violated. This idea is further captured in the analogy of the greedy institutions that straddle the worlds of family and education.

In a report on equal opportunities in higher education Acker (1980) points to the fact that both family and higher education are "greedy institutions, a concept expounded by Coser as institutions seeking "exclusive and undivided loyalty, and they attempt to reduce the claims of competing roles and status positions on those they wish to encompass within their boundaries" He notes further that their demands on the person are omnivorous. ... They exert pressure on component individuals to weaken their ties, or not to form any ties, with other institutions or persons that might make claims that conflict with their demands (Coser, 1974: 4).

In western societies like the U.S. such pressures are further institutionalized such that women with children who do not take on this special responsibility are regarded as deviant by the state and may be subject to punishment such as having their children taken into state care or having their mothering supervised (Edwards 1993). Similarly, Merrill (1999) observes that the various ways in which mature student women's multiple roles exert pressure on them "was partly constrained and shaped by both university organizational arrangements and outside institutions such as the family and work".

Although higher education institutions accept the presence and participation of students from different demographic and social backgrounds, the organizational arrangements and culture of higher education in most cases are still based on the original notion of the single, White, middle-class male student. The extent to which 
these private and public spheres stay separate both in women's activities and feelings is often hard to tell. For some women, the public life of work is seen as an extension and complement of the private life. Like some of the women in Edwards' study, the public life of work and school give African women the opportunity to put their private experience of mothering and home making into perspective. The choice of work or courses in higher education is informed by and extends from their life experiences as mothers and nurturing home makers. But as Porter (1983) states, whether or not public and private boundaries are empirically real is less important than the fact they are real in their ideological consequences. Indeed, in an expressive sense there may be "boundaries to which people actually make reference and which are meaningful to them in their everyday lives" (Morgan, 1985: 153).

\section{Why and How They Come}

The participation of African students in US higher education is a recent phenomenon that has been facilitated by changes in various immigration policies over several decades. African enrollments in US higher education are a product of the 1965 US Immigration Act that relaxed the immigration of foreigners into the country. While the Act led to an expansion of immigration into the country, it was not until the aftermath of the 1970s that a considerable number of Africans, mostly male students, began to consider the U.S. as a destination for education (Zeleza, 2008). The complex nature of foreign travel coupled with a constellation of cultural, socio-economic, and political factors both within Africa and in the US, made it difficult for African women to participate in foreign study. For one, very few women in Africa had access to higher education and training in their home countries until recently, and those who could pursue higher education were reluctant to embark on foreign travel due to various financial, social, and cultural reasons. Since the 1990s, globalization and the resultant technological development have enhanced African women's participation in foreign study.

The majority of African women often enter US higher education in stepwise fashion, often starting by following their spouses (who are often students) and gradually enrolling in higher institutions. African women are thus able to maintain their family units while pursuing their educational goals. However this double investment has significant implications for their graduate experiences, especially with regards to social interaction and networking; a point I will address in later sections below.

For many of the women, the decision to leave home was due to family reasons: the desire to join a spouse who had already been admitted into a US institution either for studies or research. For others, however, an element of chance or accident, professional and academic growth, or the availability of scholarship or financial support lay behind their choice of destination. Akua, a fourth year doctoral student of education, for instance, made the decision to join her husband who had decided to pursue a doctoral degree in a university in the Midwest after completing a master's degree in another East Coast university. She states that

For me, the only reason I am in this country in the first place is because of my husband; the thing is, he had been at this university in the East Coast for three years to do his master's and I was home with the kids. In the three years, he only came home once, just for a month. So when he decided to do a PhD here, I decided that it was time for me to join him for the sake of our marriage and the kids. That is why I am here today.

Apart from the few women who initially came to the US as students or in some other capacity, the rest of the women came to join their spouses who were either studying or on some research assignment. Many of them had never traveled overseas and some acknowledged that the possibility of furthering their education and the prestige of a US degree were motivating factors. As Neema put it:

I think the potential for me to further my education in the U.S. played a role in my considerations. Even though it was important for me to join my husband, I would not have left my career if I didn't think it was possible for me to pursue further studies.

For others like Lydia, enrolling in a graduate program was never part of the plan before she arrived in the United States. She had planned to return to her country to pursue a degree in law and had written the entrance exams and only wanted to visit her husband whom she had not seen in two years. But Lydia and her then three year old son were denied entry visas twice; only after the intervention of "a big-man" who had connections to a U.S. consular official in her country did they finally get a visa. After they finally reunited with that visit, Lydia and her husband did not want to have to go through the ordeal of securing another visa:

My husband was in a program that was going to take at least seven years to finish, and from our visa experience back home; I did not want us to go through that over again so I just decided to stay for the duration of our visas. We also wanted to expand our family, and we could not do that by being apart.

Nineteen out of the twenty three women interviewed came initially as accompanying spouses on the F-2 visa 
category, a very restrictive category that confines its holders (immediate family of the non-immigrant student) to the domestic household. In the US, holders of this visa can neither work nor study beyond grade school because of the high cost of high education. In many states, they cannot acquire drivers' licenses due to their inability to acquire social security numbers.

Mahjong Kim (2006) has argued that the policies of the U.S. Citizenship and Immigration Services are primarily responsible for the barriers that spouses of international students experience in ensuring their economic and social well- being. According to her, the immigration policies which categorize them as "dependents" are rooted in the eighteenth and nineteenth century property ownership rights whereby "political rhetoric on citizenship and economic independence was linked with political freedom and became gender specific so as to establish the prerogatives of White masculinity.; at the same time, all women and Blacks were perceived as dependents" (p. 163). For Kim, therefore, since large numbers of international spouses are women, their restriction into the private sphere seems apparent to a casual observer as being simply each sojourner's individual circumstances. For many of the women who arrived on this visa category, the restrictions associated with their status were the reason they enrolled into graduate study earlier than they had planned. For Zita, Tal, Lydia, and Ocholi, raising their young children was their first priority when they arrived; going into graduate study was a distant plan. But as Zita noted, "To live on F-2 visa is like being in prison; you can't work, you can't study and you can't even drive." Once they realize the burdens of their lives as dependents on F-2 visas, many take the steps to change their status. For those who have the prerequisites to study, enrollment into graduate study becomes the most viable option.

\section{Navigating Norms, Rules, and Regulations}

The most difficult factor of norms, rules, and regulations is an amalgam of several different responses all highlighting the difficulties associated with operating on a day-to-day basis in a foreign culture. For example, during one of the focus group meetings, several women commented that the classroom atmosphere in the US is much more informal than they were accustomed to. Specifically, students observed that US students speak out more frequently, often without being called on, and interact with their professors using more familiar terms. Most of the women agreed that, because these behaviors would be unacceptable in their home countries, it is difficult to violate these ingrained beliefs and fully participate in the classroom discussion.

Understanding the structures of their various departments (who to contact regarding issues like funding, meeting milestones, etc) has posed challenges for many women. In many graduate programs, issues concerning students' funding, preparing to meet milestones, and other related concerns are often handled by the students' academic advisors. While some advisors do a good job shepherding their students through these issues, many advisors do less than adequate jobs in guiding graduate students. In general, graduate programs often assign advisors to incoming students based on their stated interests, among other things, but the expectation is that once students settle into the program, they will eventually select a permanent advisor to direct the rest of their study. In some programs however, a graduate director is often appointed to guide all incoming students until they are able to choose their individual advisors. For those women who belonged to programs where this was the case, they acknowledged that this format made it easier for them to eventually choose a professor who was a "good fit" to guide their study. As Nadia and Nkenzie explained, the format where new students are assigned advisors 'even before they arrive' is 'very intimidating'. "... in this case, if it turns out that your "assigned advisor" is not compatible to your personality, it is very hard to change to another one". On paper, students are allowed to change to any professor as an advisor, but as Nkenze notes, "we all know that some professors have bad egos and often see such changes as an affront to their image". They go on to cite several examples of students who changed from their "assigned advisors" and had tremendous difficulty finding a new one because other professors in their view, did not want to offend the "abandoned advisor." Sonali and several other women indicated how difficult it was for a graduate student to find a new advisor or constitute an academic committee after switching from a previous one, especially when the previous student-advisor relationship did not end on a happy note.

Although the women could not understand the factors that led to positive professor-student relationships, many of them believed that their parental status was by far the most negative factor in the professor-student relationship. As Nadia observes, "For women, many professors believe that when you have children that means you are not serious about your career." Sonali talked about how her former advisor reacted when he got to know she was expecting her second child; "He just said, 'What did you do that for'...pointing to my stomach. It's so humiliating." Although some research (Mason and Gouldin 2003, Mason, 2002) has documented the impact of children on women's careers in academia, very little if any, has been done about women in graduate education as mothers. This might be because, many western women have come to accept the fact that children are a hindrance to their career advancement and often delay childbirth through their graduate school years, or forgo it altogether. 
Besides, western women are fortunate to have educational structures that allow them to get into graduate school while still in their early adulthood, hence their ability to delay childbirth at this period. For African women, however, social norms at home make having children an imperative and as one woman noted, "our children are our social security". By the time African women enroll into graduate school, most of them are often in their late adulthood. Although African norms and culture restrict childrearing to women, women who try to balance parenting and careers/further studies, especially at the graduate school level are rather valued and often admired by all as hardworking and determined. So it is very shocking for these women to comprehend the idea that they are not serious about their careers because they are raising children.

\subsection{Systemic Racism and African Women Interactions}

White domination is often rationalized by the belief that the inferiority or superiority of a group's abilities, values, and culture are linked to their physical characteristics such as skin color (Feagin, and Sikes 1994; p. 4). Being Black, African student mother cannot escape the negative stereotypes among White professors, staff, and students about Black inferiority so engrained in the U.S. society. Such perceptions are often revealed in the differential treatment and responses toward African students by professors, especially in classrooms; overt comments about African students being "affirmative babies"; meaning they were admitted not on the basis of their qualifications, but because of the institution's response to demands of affirmative action.

In their analysis of Black students' experiences in predominantly White colleges and universities, Feagin, Vera and Imani (1996) observe that "the subtle and overt distinctions that are made in everyday interactions define the character of the social position one occupies in interaction with others" (p. 94). In my interviews with African graduate student mothers, this theme was echoed by many. An African woman describes her experience of indifference and marginalization in a graduate seminar taught by a White professor:

I took this seminar on research methods with this guy....it was just three of us out of 11 students that were not white. The two of us who were Black, one was an African American guy and the other student was Asian looking, she could have been bi-racial...I don't know that for sure, but I could tell by her Americanized accent that she probably was born here or grew up here...but anyway, it was just the three of us from non-White backgrounds. For the first six to eight weeks, I realized this man ignored every comment or contribution I made in class. Any time I raised a point, he will just keep quiet and either ask another student or move the discussion on to another focus. At first, I thought that was just his policy not to affirm or dispute any point of view that students raised, but as the class progressed, I noticed he would heartily commend the good points that the other White kids made but when I make a point, everybody acted like I did not exist in the class. But when the same point that I raised earlier is mentioned later by another student, the professor will make comments like, 'That was insightful.' At first, I thought maybe it was because I spoke in an accent that may not be understood, but as time went by; I just noticed it was a deliberate action to make me feel invisible." (R.I., 12/11/2009)

This student went on to explain how she had to interrupt the discussion one day after a point she had made was ignored by the professor, only for another student to state the same point shortly after and received positive compliments by the professor: "But a few minutes later, another White girl basically repeated verbatim, what I said earlier, and this man went ecstatic with praise for the great insight the girl had...I just couldn't ignore it anymore." (R.I., 12/11/2009)

To some White professors, the African woman in graduate school is nothing more than an accident of some diversity or affirmative action policies. Unlike African American women who are viewed as domineering, African women are perceived by White professors as timid and subdued creatures who lack self confidence and initiative; two key ingredients necessary for a successful graduate study. A senior faculty in the college of education once told me during an interview for a research assistantship he advertised that he finds it difficult to believe that African women can be self-directing since they have lived all their lives under the yokes of their fathers and husbands.

You know this job requires self initiative and motivation (he said) and I find it difficult to imagine that the spirit you show here today can be sustained....I hardly come across African women and ....I think it's a total waste of resources to fund such women since their only purpose is to serve their husbands and give birth to countless children.

It may well be that this particular professor is just downright nasty and his actions may not reflect the majority who work with African students daily. But even the attitudes of well meaning professors sometimes convey nothing more than a lack of interest.

Describing some of her experiences, Acholi, a fourth year African student mother of three notes:

You know, sometimes I don't know what to call the reaction that I get when I meet with some professors. You 
probably have faced such a thing before... where you go to meet with a professor, and after saying what you want to say for about 3 minutes, you get this attitude of 'what did you say?' ... It looks like as soon as you start to speak, they tune off their ears and minds... In total black-out until you are done, then they turn back on as if they just recovered from some trance.

This "zoning out" attitude, as I call it (Lobnibe, 2009), has become a common experience for many African women in US graduate schools. What is interesting in the case of these women is the fact that their experiences are not only limited to their interactions with Whites. Other non-European international students have come to share in the racial frame of Blacks as intellectually inferior to others. One of my respondents shared her story about her friendship with an Asian international student who asked her why African students are not into the "smart courses" like engineering and science. Although these accounts may point to individual prejudices and bigotry, it is obvious that such feelings, biases, and stereotypes are widespread and ultimately influence the individual's ability to form meaningful alliances with others within the institution.

\subsection{Systematic Discrimination and African Women}

In many ways, the women in this study were visible in ways they did not wish to be seen, and are rendered invisible when they seek recognition and belonging. The contrast between who they think they are, and how they are treated, creates dissonance in how they perceive themselves throughout their study. Some resist by withdrawing, and others endure the suffering silently. In their work on how Black middle class experience life in White working environments, Feagin and Sikes (1994) point to the subtle forms of exclusion that works to bar Blacks from professional positions. Drawing on the insight of Thomas Pettigrew, they note that "Racial discrimination is basically an institutional process of exclusion against an out-group on largely ascribed and particularistic grounds of merit" (p. 19). While Whites may have the power to discriminate as individuals, they argue, much of their power to harm comes from membership in White-dominated organizations and social networks. In one respondent's statements in their work, he notes that:

You may move into an environment and not know the rules, and therefore not know how to play the game and not know how to succeed....the barriers and obstacles are often that people will not allow you into the inner circle. ....the students who get the best grades are the students who know how to talk to the law professors. They know how to call on their fathers, brothers, and uncles to introduce them into the profession...." (Feagin and Sikes, 1994, p. 141)

Like the respondent quoted above, African women experience similar exclusion from the inner circles within and outside of their departments. For these women, however, the discrimination and racism they face is not only in the hands of White professors, students, and staff; as one respondent notes, "You would think that it is only Whites who are always racists, but I can swear that the African Americans and Latinos are more vicious and blatant in their disdain for us than the Whites". This particular student goes further to explain the difference between "White racism" and "Black racism" toward African students:

The difference is that, for White professors and students, you are often seen as not smart enough to be in graduate school; let me even say that you are not considered to be human, you don't exist!...and when you have an occasion to prove that you might even be smart, you are still a backward person in their mind. But for the African Americans, you are often seen as a threat to their material and economic resources. You often hear comments like 'We (African Americans) fought for affirmative action only for you (Africans) to come and enjoy after you sold us (African Americans) out as slaves.' So because they believe that the benefits of what their ancestors toiled for should be reserved for only African Americans, they feel resentment that we are here today and some even think that we are better treated by the Whites than they are. (R.2.: 12/19/2009)

It seem that while African women may experience discrimination from both White and Black American professors and students, the reasons or motivations behind these actions differ between Whites and Blacks. On the one hand, Whites view these women as inferior and not graduate material to work with. On the other hand, Blacks see them as competitors over resources and opportunities they (African Students) do not deserve. Among other international students also, they are perceived as inferior, a view similar to the White group. All of these perceptions and actions have been shaped by the colonial experience and the discourse that present the African native as barbaric and backward - they can be trained in useful skills to do certain tasks, but can never be smart enough to shed off the backwardness. How all of these factors affect these women and their ability to network in their institutions is the focus of the next section.

\section{Networking and African Women}

Graduate study in the U.S. is structured in such a way that individuals have to form or belong to some kind of group 
in order to survive. From class discussions or assignments to research assistantships and forming academic committees, students form alliances with other individuals in order to succeed. Unlike African- American students in predominantly White institutions, African women do not usually have such avenues or organizations like study groups, sorority groups, or black cultural houses with which to interact, network, and develop effective coping mechanisms for their environment. In a situation where professors hold negative stereotypes about certain groups of students, it becomes difficult for such students to get closer to professors and for the professors to know the actual strengths and weaknesses of these students.

Networking allows individuals to interact and share sentiments with others who have similar characteristics (Lin 1982). Although African students in general are viewed in U.S. institutions as a group, they vary greatly in language, culture and other demographic features except the color of their skin (which is also questionable). In fact, when it comes to similar characteristics and the principle of homophily, African women are no more similar among themselves than they are to other racial groups in the U.S. Therefore the idea that they are more likely going to network with other African students is a farfetched one. Overall, U.S. higher education institutions are beset with racial and other forms of stratification which affect the nature of interactions between groups of individuals. This limitation in social interaction in turn influences the nature of ties individuals' form which often turn out to be homogenous (comprising members from similar racial-ethnic and often gender backgrounds). Let us now examine the context within which African women may interact and network.

\section{Identity and African Women Interactions}

African women in US institutions are forced to come to terms with notions of Africanity for the first time as well as the burden of representing "all things African" in popular discussions and other social contexts. On the continent, most people in rural areas live under social categories: some educated, middle class, or urban dwellers may see themselves as members of a nation. It is in the U.S. (and other western contexts) that a Nigerian Igbo, a South African Zulu, and a Kenyan Kikuyu suddenly and unequivocally become Africans. The condition of Africanity both marginalizes and expands the African woman's horizons at the same time. She is no longer an Acholi or a Ugandan but an African - a member of that mythical race created by the White imagination as a foil and a justification for the holocaust of slavery and colonial exploitation (Nesbitt, 2002). She is not only responsible for Somalia, Congo, and Sierra Leone but also tied inexplicably to the inner city street harlot and drug addict.

The result is that most African student mothers must negotiate new identities that can no longer depend on the security of nationality and ethnicity familiar to them in their homeland nor are they able to assume African-American identities. Some have approached this identity confusion by carefully avoiding clothing that expose some body parts or look "too sexy". Rather they emphasize their "Africanness" by wearing garments made from "home." Doing so, however, also exposes them to what Nbu describes as "vilifications from our African American brethren" and others who consider Africans as backward and barbaric. Furthermore, by being constructed as representatives of their cultures, they are being made to bear what various scholars of race have called the "burden of representation." As with the experiences of Black American students in White colleges explored by Feagin.et al (1996), African women often find themselves in situations where they have to act as "defenders and explainers of their group". When American (mostly White) professors attempt to include minority students in class discussions, it is often done in ways that place enormous pressure on them to represent their entire social group. One African woman notes:

I had this class where the professor will always ask me how people in Africa do this or that....even when the issue is basically a general idea. I find it ridiculous that this woman (professor) would think that there is an African version to everything. I had to point out some day that examples I may give cannot even be representative of my country let alone the entire continent. (RI: 12/11 2009).

The university environment is a microcosm of the structures of and discourses on cultural relations prevailing in the wider social arena. Accordingly, "citizenship" in the university is accorded to "real" Americans, the locals who are culturally neutral. Students like African women whose culture is visibly different and seen as "foreign" are not really a part of the university. They should be "accommodated" but they only aspire to citizenship in the university community. They are not able to have citizenship by virtue of their visible difference. Cultural and racial difference impose limitations on agency as stereotyping, exclusion, and other forms of discrimination create views of the self that are difficult to transcend. African women are often less prepared for the pervasive racism and second class status that they have to overcome in U.S. institutions.

Human agency may be frail, especially among those with little power, but it happens daily and mundanely, and it deserves our attention. As Holland et. al (1998: 5) observe, humans' capacity for self-objectification — and through objectification, for self direction-plays into both their domination by social relations of power and their 
possibilities for partial liberation from these forces. As I listened to their stories, one of the strong impressions the student mothers left on me was a sense of their strength and resilience. Even when the women were talking about difficult circumstances and appeared to be vulnerable, and at times sad, they did not convey a sense of weakness or of victims. Their silence did not appear to come from voicelessness or lack of agency, but rather from choice. As some of them make clear, they drew strength from knowing that their experiences were only temporary and would end with enormous reward when they graduated and went back home. Others balanced out the poor classroom relationships by seeking social connections outside of the classroom; mostly among parents of their children's friends or church members.

\section{Conclusion}

This paper has sought to demonstrate how in the US higher education context, institutions often structure their physical, academic, and cultural values to fit this idea of public and private dichotomy, so that educational institutions separate formal educational knowledge from knowledge acquired through living by treating experience as a faulty representation of theory and theory as the "real reality. Such a separation has some implications for relations of gender in many universities where the faculty and the professoriate have historically been structured for the life of the male scholar, requiring re-adjustment to accommodate the realities of the lives of females who, at the very same time that they are coming into their own as academics, have their biological clocks ticking. It has argued that apart from the fact that things have hardly changed for women more generally, the challenges faced by the foreign international African student mother whose gender and region is stereotyped in the popular imagination of the US academe can be more daunting.

Particular attention has been paid to the experiences of African graduate student mothers, to highlight the difficulties they face in adjusting and being accepted in the US higher educational system, and to show how they in turn respond, interpret and negotiate their experiences. In addition to the challenges that all international students (and mothers) generally face in graduate school, the recency of their entry in US higher education and their intersectional identities as mothers and spouses-- bound by the cultural expectations of their home origin make their experiences worth studying. Moreover, unlike other international students, who have had experience adjusting to the socioeconomic and cultural challenges that define them as foreigners and international students, most African graduate student women are only now coming to terms with the US higher institutions, and in the process often find themselves living with either their spouses or as single mothers. These challenges are bound to shape the nature of their experiences in graduate school quite differently from those of other graduate students.

\section{Acknowledgement}

I will like to acknowledge the financial support of the PEO international peace scholarship for coursework that subsequently led to this line of research. The detail and constructive feedback from the anonymous reviewer(s) are deeply appreciated. I am also grateful to Professor Isidore Lobnibe for valuable comments and feedback on this article.

\section{References}

Arthur, A. J. (2000). Invisible sojourners: African immigrant diaspora in the United States. Westport, Connecticut: Praeger.

Coser, R. L. (1974). Greedy institutions: Patterns of undivided commitment. New York: Free Press.

Dei, G. J. S. (1996). Anti-racism: Theory and practice. Halifax: Fernwood.

Dei, G. J. S., \& Calliste, A. (2000). Power knowledge and anti-racism education: A critical reader. Halifax: Fernwood.

Dei, G. J. S., Asghazadeh, A., Bahador, S. E., \& Shahjahan, R. A. (2006). Schooling and difference in Africa: Democratic challenges in a contemporary context. Toronto: University of Toronto Press.

Edwards, R. (1993). Mature women students: Separating or connecting family and education. London: Taylor \& Francis.

Erez, M., \& Earley, P. C. (1993). Culture, self-identity and work. Oxford University Press. http://dx.doi.org/10.1093/acprof:oso/9780195075809.001.0001

Feagin, J. R. (2006). Systemic racism: A theory of oppression. New York: Routledge.

Feagin, J. R. (2002). The continuing significance of racism: U. S. colleges and Universities. Washington D.C.: American Council on Education.

Feagin, J. R., Vera, H., \& Imani, N. (1996). The agony of education: Black students at white colleges and 
universities. New York: Routledge.

Feagin, J. R., \& Sikes, M. P. (1994). Living with racism: The black middle-class experience. Boston: Beacon Press.

Hurtado, S., Milem, J., Clayton-Pederson, A., \& Allen, W. (1998). Enhancing campus climates for racial/ethnic diversity: Educational policy and practice. The Review of Higher Education, 21(3), 279-310. http://dx.doi.org/10.1353/rhe.1998.0003

Kim, M. (2006). Forced into Unpaid Care Work: International Students' Wives in the United States. In M. K. Zimmerman, J. S. Litt, \& C. E. Bose (Eds.), Global Dimensions of Care Work and Gender (pp. 163-175). Palo Alto, CA: Stanford University Press.

Leathwood, C., \& O'Connell, P. (2003). It's a struggle: The construction of the 'new student' in higher education. Journal of Educational Policy, 18, 597-615. http://dx.doi.org/10.1080/0268093032000145863

Levine, A., \& Nidiffer, J. (1996). Beating the odds: How the poor get to college. San Francisco: Jossey-Bass Publishers.

Lin, N. (2000). Inequality in social capital. Contemporary Sociology, 29, 785-795. http://dx.doi.org/10.2307/2654086

Lobnibe, J. F. (2009). International Students and the Politics of Difference in US Higher Education. Journal of Critical Educational Policy Studies, 7(2), 347-368. Retrieved from http://www.jceps.com/PDFs/07-2-13.pdf

Lovitts, B. E. (2005). Being a good course-taker is not enough: A theoretical perspective on the transition to independent research. Studies in Higher Education, 30, 137-154. http://dx.doi.org/10.1080/03075070500043093

Mason, M. A., \& Goulden, M. (2002). Do babies matter: The effect of family formation on the lifelong careers of academic men and women. AAUP Publications. Retrieved from http://www.aaup.org/publications/academe/2002/02nd/02ndmas.htm

Merrill, B. (1999). Gender, change and identity: Mature Women Students in Universities. England: Ashgate.

Morgan, D. H. J. (1985). The family, politics and social theory. London: Routledge.

Rizvi, F. (2005). Identity, Culture and Cosmopolitan Futures. Higher Education Policy, 28, 331-339. http://dx.doi.org/10.1057/palgrave.hep.8300095

\section{Note}

Note 1 . Because of the intimate nature of the topic, the site of the research is intentionally masked, and all the names used throughout the paper are pseudonyms to ensure the confidentiality of informants. 